\title{
ARMAZENAGEM E GANHOS LOGÍSTICOS: UMA ANÁLISE COMPARATIVA PARA COMERCIALIZAÇÃO DA SOJA EM MATO GROSSO DO SUL
}

\author{
Ana Paula Dalmagro Delai" \\ Jaylton Bonacina de Araujo** \\ João Gilberto Mendes dos Reis*** \\ Luciana Ferreira da Silva ${ }^{* * * *}$
}

RESUMO: O presente artigo tem como objetivo analisar a melhor estratégia que o produtor de soja, do município de Amambai, no Estado de Mato Grosso do Sul, pode obter maior vantagem logística com a venda ou armazenagem dos grãos. A pesquisa utilizou-se de metodologia exploratória e descritiva de dados secundários referentes aos preços de frete, armazenagem, produção de soja e preço da saca para as safras de 2012/2013, 2013/2014 e 2014/2015. Além destes, foram utilizados dados primários, coletados por meio de entrevista aos produtores rurais de uma cooperativa da região. Os resultados obtidos apontaram que existe grande incerteza quanto ao tempo de armazenagem, dado que os custos com armazenagem e frete impactam diretamente na receita final do produtor. A pesquisa demonstrou também que devido à oscilação de preços da soja, a armazenagem torna-se necessária. Finalmente verificou-se uma maior rentabilidade quando a comercialização foi realizada 30 dias após a colheita.

PALAVRAS-CHAVE: Agronegócio; Armazenagem de grãos; Logística; Soja.

\section{STORAGE AND LOGISTIC PROFITS: A COMPARATIVE ANALYSIS FOR SOYBEAN COMMERCIALIZATION IN THE STATE OF MATO GROSSO DO SUL}

ABSTRACT: The best strategy whereby soybean producers in Amambai in the state of Mato Grosso do Sul, Brazil, may have the best logistic advantage by selling or storing grain is analyzed. Research employed exploratory and descriptive methodology of

\footnotetext{
* Mestre em Agronegócios; Docente convocada do curso de Administração da Universidade Estadual de Mato Grosso do Sul (UEMS), Brasil; E-mail: anapauladelai@hotmail.com

** Doutorando do Programa de Pós-graduação em Engenharia Mecânica e de Materiais (PPGEM) da Universidade Tecnológica de Paraná (UTFPR), Brasil.

${ }^{* * *}$ Doutor em Engenharia de Produção pela Universidade Paulista; Docente titular da Universidade Paulista UNIP e docente do Mestrado em Agronegócios da Universidade Federal da Grande Dourados (UFGD), Brasil.

**** Doutora em Economia Aplicada pela Universidade Estadual de Campinas; Docente adjunto da Universidade Estadual de Mato Grosso do Sul (UEMS) e docente do Mestrado em Agronegócios da Universidade Federal da Grande Dourados (UFGD), Brasil.
} 
secondary data on freight and storage prices, soybean production and price of sack for the 2012/2013, 2013/2014 and 2014/2015 harvests. Primary data collected in interviews with producers of a cooperative in the region were also used. Results showed great uncertainty with regard to storage time, a datum that storage and freight costs directly impact the producers' income. Research revealed that storage is a must due to oscillations in the price of soybean. A greater income has also been reported when commercialization occurred 30 days after harvest.

KEY WORDS: Agribusiness; Grain storage; Logistics; Soybean.

\section{INTRODUÇÃO}

O Brasil se destaca como o segundo maior produtor mundial de soja, com uma produção de cerca de 94.500 mil toneladas na safra 2014/2015. Em 2014 o país exportou cerca de 46.688 mil toneladas, tendo como principal destino a China, que corresponde a 70\% das exportações brasileiras (ALICEWEB, 2015; CONAB, 2015a; USDA, 2015).

Hirakuri e Lazzarotto (2011) apontam que a sojicultura está entre as atividades produtivas de maior destaque no contexto mundial e nacional. Devido a sua importância, a soja apresenta crescimento tanto em produtividade, como em área plantada, em virtude dos avanços tecnológicos utilizados no processo produtivo.

A região Centro-Oeste, por sua vez, é a principal região produtora do país, sendo que na safra 2013/2014 sua produção representou 48\% do total nacional, e 42\% da soja exportada (ALICEWEB, 2015; CONAB, 2015b). Dentre os Estados que compõem a região, Mato Grosso do Sul possui a terceira maior produção de soja do Centro-Oeste e a quinta maior do Brasil.

A cultura começou a receber grande atenção no Estado a partir da década de 1970, expandindo sua área cultivada e produção desde então (PAVÃO, 2005; FAGUNDES; SIQUEIRA, 2013). Em 2014, as lavouras sul-mato-grossenses de soja ocupavam em torno de 2.120 mil hectares, correspondendo a uma produção de 5.809 mil toneladas na safra 2012/2013. O Estado exportou um total de 2.430 toneladas, representando um valor total de US\$ 1,229 bilhão (CONAB, 2015b).

A maior parte do escoamento da produção de soja da região Centro-Oeste 
ocorre via modal rodoviário, sendo o principal modal utilizado para o transporte de cargas no Brasil (CORREA; RAMOS, 2010). O Estado de Mato Grosso sendo o maior produtor desta commodity, e na busca por menores custos logísticos no processo de escoamento da produção, recorre à utilização do chamado Corredor Noroeste, composto pelas rodovias federais do Estado e da hidrovia rio MadeiraAmazonas (SILVA; MENEZES, 2008). Em Mato Grosso do Sul, as principais rodovias utilizadas são a BR 163, que atravessa o Estado de Norte a Sul, desde o município de Sonora até o município de Mundo Novo; BR 267 que parte de Porto Murtinho com destino ao Estado de São Paulo; e a BR 262 que vai desde Corumbá até Três Lagoas (MINISTÉRIO DOS TRANSPORTES, 2015).

De forma a compensar os custos de transporte da soja, a armazenagem de produtos agrícolas além de proporcionar a manutenção da qualidade destes produtos e evitar perdas, permite ainda uma melhor estratégia de comercialização, incrementando os lucros dos produtores, pelo fato de ser possível realizar a venda dos mesmos nas épocas de entressafra, quando os preços são mais altos, bem como aproveitar o benefício do valor do frete via modal rodoviário que é mais baixo do que no período da safra (ROCHA et al., 2012; NOGUEIRA JUNIOR; NOGUEIRA, 2007).

Em Mato Grosso do Sul, conforme dados da CONAB (2015c), existem um total de 861 armazéns, com uma capacidade estática total de 8,3 milhões de toneladas de grãos. Destes armazéns cerca de $78 \%$ são do tipo granel e $22 \%$ convencional.

Este artigo busca responder, diante desse cenário, como o produtor de soja pode obter maiores ganhos logísticos após a colheita da safra. Para tanto o objetivo da pesquisa é analisar qual a melhor estratégia que o produtor de soja, da região de Amambai, no Estado de Mato Grosso do Sul, pode obter maior ganho logístico através da venda ou armazenagem, após a colheita.

$\mathrm{O}$ artigo está organizado em quatro seções, incluindo esta introdução. $\mathrm{Na}$ segunda seção é exposta a metodologia utilizada para a realização da pesquisa. A terceira seção é composta pelos resultados obtidos e a discussão sobre os mesmos. E a quarta seção apresenta as considerações, destacando os principais resultados da pesquisa. 


\section{METODOLOGIA}

Como método, este estudo enquadra-se como pesquisa exploratória descritiva (PRODANOV; FREITAS, 2013), utilizando-se de dados primários e secundários de fontes como: Companhia Nacional de Abastecimento (CONAB), Instituto Brasileiro de Geografia e Estatística (IBGE), Sistema de Informações de Fretes (SIFRECA), Sistema de Informações de Armazenagem (SIARMA), e Centro de Estudos Avançados em Economia Aplicada (CEPEA - ESALQ/USP).

A pesquisa exploratória é conduzida utilizando um estudo de caso para a criação dos cenários, buscando assim testar a hipótese de que se a venda da produção de soja ocorrer em época de melhor preço então há maiores ganhos logísticos para o produtor.

O estudo compreende uma análise de três anos entre as safras 2012/2013, 2013/2014 e 2014/2015. Assim, foi necessário levantar uma série histórica de valores de fretes de soja a granel para as rotas de transporte das fazendas para a cooperativa, sendo este o destino final para armazenagem ou para venda, considerado no estudo. Para a coleta destes dados foi utilizado o Sistema de Informações de Frete (SIFRECA, 2015) como base, além de entrevistas transcritas, realizadas com os associados nas sedes da cooperativa A do município.

Posteriormente foi realizado o levantamento dos custos de armazenagem dos cooperados, além da coleta de dados disponibilizados pelo Sistema de Informação de Armazenagem (SIARMA, 2015), referentes aos custos de recebimento e armazenagem.

Para a análise do preço da saca de soja foi avaliado e padronizado o período de maior índice de colheita de soja no município com base no calendário agrícola, determinando assim o mês de fevereiro como o mês de maior colheita, com 85\% de área colhida, ficando cerca de $15 \%$ colhidos em janeiro.

Os dados referentes ao preço da soja foram obtidos por meio do índice CEPEA (ESALQ/USP, 2015) expressos em $\mathrm{R} \$ /$ saca. A fim de facilitar a análise, foi preciso padronizar os valores, convertendo-os em $\mathrm{R} \$ /$ tonelada, haja vista que os valores de frete e armazenagem também estavam representados na unidade $\mathrm{R} \$$ / tonelada. Após a padronização dos valores de custos, foi calculada a Receita Líquida 
da operação, considerando como receita o valor da venda da produção, subtraindo os valores de frete e armazenagem, chamados de custos.

A pesquisa foi desenvolvida em uma amostra de produtores rurais atuantes no mercado por meio de associação na cooperativa do município, aqui descrita como cooperativa A. Utilizou-se como referência para estimativa da amostra o cálculo do número de indivíduos, segundo Bisquerra, Sarriera e Martinez (2004), apresentado em (1).

$$
n=\frac{\sigma^{2} p \cdot q \cdot N}{e^{2}(N-1)+\sigma^{2} \cdot p \cdot q}
$$

Onde:

$$
\begin{aligned}
& n=\text { Amostra; } \\
& \sigma=\text { Desvio padrão; } \\
& p . q=\text { Porcentagem pela qual o evento ocorre; } \\
& N=\text { População; } \\
& e=\text { Erro. }
\end{aligned}
$$

A cooperativa conta com um total de 210 cooperados, sendo 39 produtores de grãos; destes, 73\% são residentes em Amambai. Portanto, para esta pesquisa, adotou-se uma população de 39 cooperados dada a facilidade de acesso aos mesmos. A amostra então foi calculada considerando desvio padrão igual a 2 e erro de $10 \%$ para suas estimativas, o que representou 28 cooperados.

Para atender ao objetivo desta pesquisa, foram elaborados, por meio do uso do software Microsoft Excel ${ }^{\circledR}$, quatro cenários com diferentes períodos de armazenagem e comercialização da produção de soja no município. O primeiro cenário refere-se à venda da produção após a colheita, sem armazenagem; o segundo concerne à armazenagem de 30 dias, comercializando a produção em março; o terceiro cenário refere-se à armazenagem de 60 dias, comercializando a soja em abril; e o quarto considera uma armazenagem de 90 dias com venda em maio, como segue na Quadro 1. 
Quadro 1. Cenários para análise deste estudo

\begin{tabular}{|l|c|c|c|c|c|c|}
\hline & \multirow{2}{*}{$\begin{array}{c}\text { Sem } \\
\text { armazenagem }\end{array}$} & \multicolumn{4}{|c|}{ Com armazenagem } & \multirow{2}{*}{$\begin{array}{c}\text { Período de } \\
\text { venda }\end{array}$} \\
\cline { 3 - 6 } & Fevereiro & Março & Abril & Maio & Após colheita \\
\hline Cenário 1 & $\mathrm{X}$ & $\mathrm{X}$ & & & & Final de Março \\
\hline Cenário 2 & & & $\mathrm{X}$ & & & Final de Abril \\
\hline Cenário 3 & & & & $\mathrm{X}$ & & Final de Maio \\
\hline Cenário 4 & & & & & $\mathrm{X}$ & \\
\hline
\end{tabular}

Fonte: Elaborado pelos autores.

Os cenários foram replicados nos três anos analisados nesta pesquisa com a finalidade de comparar as Receitas Brutas obtidas em cada cenário de cada ano e apontar qual apresentou maiores vantagens de logística, ou seja, maior Receita Líquida.

Após a elaboração dos cenários foi organizado um roteiro de entrevistas a ser aplicado aos associados da cooperativa $\mathrm{A}$, estimados na amostra, com a finalidade de coletar dados referentes ao volume produzido nas propriedades nos anos analisados, além de obter informações sobre custos de frete e custos de armazenagem.

$O$ roteiro de entrevista foi organizado de maneira clara e objetiva, com perguntas diretas estruturadas em um módulo, a fim de atender o objetivo desta pesquisa que é avaliar em qual momento após a colheita da soja o produtor obtém maiores ganhos logísticos na venda de sua produção. Definida a estrutura do roteiro de entrevista, o mesmo foi aplicado no período de plantio da safra 2015/2016, ou seja, entre os dias 15 de setembro e 25 de outubro na sede da cooperativa A, local definido pela facilidade de acesso aos cooperados. Neste período foi possível o contato com 28 cooperados, correspondente ao valor estimado no cálculo da amostra.

\section{RESULTADOS E DISCUSSÃO}

A área a ser estudada nesta pesquisa compreende o município de Amambai, localizado na região Sudoeste do Estado de Mato Grosso do Sul, a uma distância de 
$382 \mathrm{~km}$ da capital do Estado, Campo Grande. De acordo com dados da Prefeitura de Amambai (2015), o município possui uma população de 35.523 habitantes, sua geografia física apresenta solo de terra roxa em uma região de relevo levemente ondulado, de clima tropical com temperatura média de $22{ }^{\circ} \mathrm{C}$, estando sob influência da Bacia do Rio da Prata.

A economia local é movida pela agropecuária, sendo a pecuária representada por um rebanho de 350 mil bovinos, e a agricultura com 30 mil hectares cultivados. Segundo Galvan et al. (2013), o município de Amambai encontra-se em uma região de destaque no cultivo da soja, onde na safra 2011/2012 apresentou 50 mil hectares de área plantada com $2.110 \mathrm{~kg} / \mathrm{ha}$ de produtividade.

Em 2012, o município de Amambai, segundo dados da PAM (Pesquisa Agrícola Municipal) elaborada pelo IBGE (2015), obteve uma produção de soja de 89.100 toneladas, e no ano de 2013 a produção somou 171.810 toneladas, apresentando um crescimento de 51,9\%. Conforme dados obtidos por meio das entrevistas, no ano de 2014 a produção de soja no município foi de 194.880 toneladas e em 2015 a safra resultou na produção de 221.550 toneladas, um crescimento de $77,5 \%$ comparado ao ano de 2013.

A evolução da produção no município refere-se, de acordo com a Secretaria de Produção e Agricultura Familiar - SEPAF (2015), a fatores como tecnologias aplicadas no campo que contribuem para a tomada de decisão, sendo ela de atraso ou não no plantio, bem como interferência do clima, com maior ocorrência de chuvas em períodos estratégicos.

Os produtores de Amambai vêm investindo em pesquisas de manejo e adequação da produção ao clima e solo da região, utilizando assim tecnologias que favorecem a tomada de decisão, tanto no plantio, no manejo e na colheita, a fim de garantir maior produtividade. Resultado percebido nesta pesquisa, a partir de 2013 quando a produção obteve crescimento significativo.

\subsection{TRANSPORTE ATÉ A COOPERATIVA}

A responsabilidade pelo transporte da propriedade rural até o silo da cooperativa é, em todos os casos, do produtor. A distância média percorrida entre 
a propriedade e a cooperativa é de $40 \mathrm{~km}$ e o meio de transporte utilizado são, na maioria, carretas com capacidade de transportar 37 toneladas, ou seja, 617 sacas. Em alguns casos o transporte pode ocorrer com veículos próprios, porém, entre os entrevistados, o transporte acontece por meio da contratação de caminhoneiros autônomos para a prestação de serviço.

Os valores de frete no município são cobrados para distância média de 40 $\mathrm{km}$, variando entre $\mathrm{R} \$ 8,34$ por tonelada e $\mathrm{R} \$ 15,00$ por tonelada, de acordo com os picos de colheita e demanda.

Os produtores aqui entrevistados afirmam ainda que o valor do frete acaba sofrendo variações durante o período da colheita, encarecendo nos períodos de pico, fato percebido em todos os anos-safra analisados. Rocha et al. (2012) apontam em sua pesquisa que os valores de frete tiveram aumento em momentos de pico de colheita, devido à necessidade de escoamento da produção, consequentemente aumentando a demanda por este serviço.

O Projeto Benin, realizado pela ESALQ-LOG (2014), apresenta uma pesquisa conduzida no Estado do Paraná, apontando por meio de entrevistas com produtores e responsáveis por armazéns que os custos com frete são altos em decorrência da má qualidade das estradas e tem provocado perdas de produtos no transporte tanto da fazenda até o armazém, como também até os portos, perdas estas que não são mensuráveis.

Portanto, os valores de frete apresentam alta em períodos de maiores índices de colheita além de sofrerem influências de fatores como má qualidade das estradas e necessidade da prestação do serviço, contribuindo assim para a insatisfação dos produtores com relação aos valores de fretes cobrados, o que justifica a necessidade de análise antes da tomada de decisão.

\subsection{ARMAZENAGEM NA COOPERATIVA}

Para analisar os ganhos logísticos que o produtor poderia obter com a comercialização da sua produção, foram analisadas as tomadas de decisões nos anossafra de 2012/2013, 2013/2014 e 2014/2015. A escolha pelos três anos-safra descrita foi definida com base na disponibilidade de dados dos produtores cooperados. 
Outro fator determinante foi com relação à capacidade de armazenagem da cooperativa estudada, que a partir de 2013 aumentou sua capacidade e estabilizou em 350 toneladas.

Com base nos anos avaliados, foi necessário definir cenários para a análise de ganhos logísticos. Portanto, foram definidos três cenários, onde ocorre a armazenagem da produção dos cooperados entrevistados e a venda de parte da produção em cada cenário. Houve ainda a necessidade de simular a venda total da soja armazenada após a colheita de cada ano, para avaliar qual tomada de decisão traria além de menor custo logístico, maior rentabilidade.

No Gráfico 1 encontram-se os custos de armazenagem dos cenários 2, 3 e 4, nos três anos-safra analisados. Para cada cenário considerou-se o custo referente à quantidade de soja armazenada e vendida em cada um dos cenários.

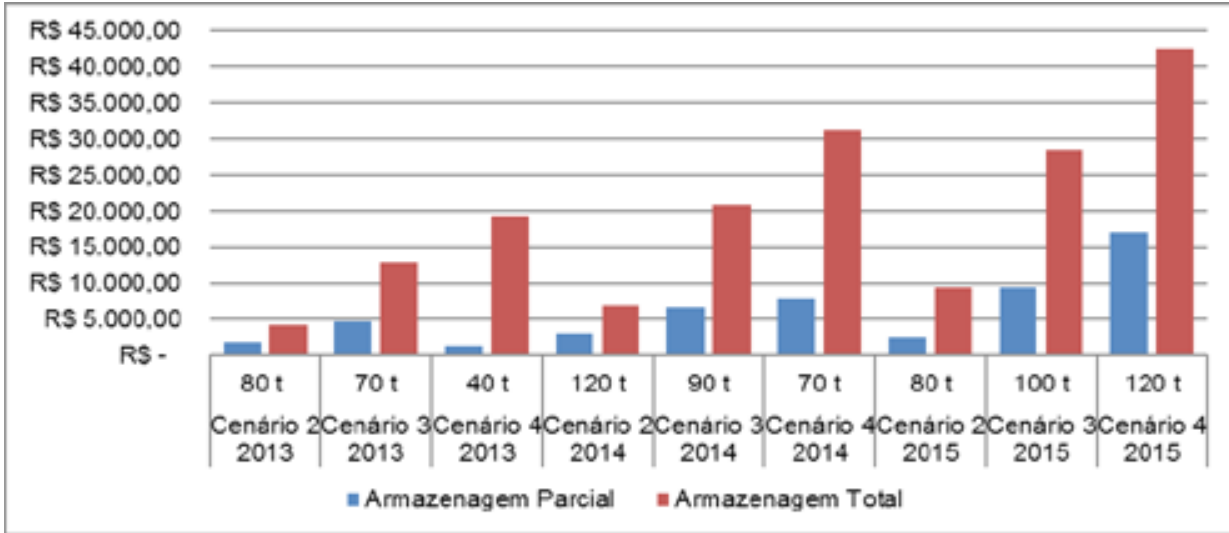

Gráfico 1. Custo por toneladas para o total de dias de armazenagem Fonte: Elaborado pelos autores.

No ano de 2013 os produtores totalizaram uma armazenagem de 190 toneladas, e durante o período analisado foram comercializadas 80 toneladas no cenário 2, 70 toneladas no cenário 3 e 40 toneladas no cenário 4 . Em 2014 a armazenagem foi de 280 toneladas, sendo comercializadas 120 toneladas no cenário 2, 90 toneladas no cenário 3 e 70 toneladas no cenário 4. A armazenagem em 2015 foi de 300 toneladas, sendo no cenário 2 comercializadas 80 toneladas desse total armazenado, 100 toneladas no cenário 3 e, no cenário 4, 120 toneladas. Foi preciso 
também estimar o custo total de armazenagem, caso os produtores tivessem vendido toda a produção armazenada em cada cenário, de forma a parametrizar com as receitas e avaliar ao todo qual a melhor estratégia a ser adotada pelo produtor.

Segundo Rocha et al. (2012) grande parte dos produtores de grãos no Brasil não possuem armazéns próprios, sendo necessária a utilização de silos e armazéns convencionais de cooperativas ou demais instituições agrícolas. Neste estudo, todos os produtores entrevistados afirmam não possuir armazéns em suas propriedades, portanto, são associados em diferentes cooperativas para que assim tenham alternativas de vender para uma e armazenar em outra. Como pode ser percebido no Gráfico 1, de um ano para o outro houve um aumento na quantidade armazenada. Tal comportamento pode ser justificado principalmente pelo aumento da produção e pela preferência dos cooperados em armazenar parte da produção para negociação em períodos com preços mais elevados.

Pesquisas como as de Rocha et al. (2012) e Dambrósio et al. (2009) apontam que, quanto maior o tempo no armazém, maior é o custo com este serviço, valor este que pode ser compensado pela alta do preço da soja no mercado. Os produtores entrevistados afirmam vender maior parte da produção ainda antes do plantio ou logo após a colheita para assegurar a quitação de empréstimos e demais gastos com a safra e optam por armazenar uma parte menor a fim de obter melhores ganhos em momentos distintos antes do próximo plantio.

Como os custos de armazenagem têm grande influência na receita do produtor, a análise feita em pesquisas como a dos autores Rocha et al. (2012) e Drambósio et al. (2009) corrobora com esta pesquisa, pois mostram que apenas terá ganhos com uma armazenagem prolongada aquele produtor que comercializar a soja com preços mais elevados do que os praticados imediatamente após a colheita.

\subsection{COMERCIALIZAÇÃO DA PRODUÇÃO DE SOJA}

A busca por melhores resultados de produtividade de soja a cada safra é justificada pela valorização desta commodity no mercado interno e externo. Neste estudo buscou-se analisar os ganhos logísticos por parte do produtor durante a comercialização, avaliando custos de frete e armazenagem e a receita líquida. No 
Gráfico 2 estão representados os preços em $\mathrm{R} \$$ por saca nos três anos analisados.

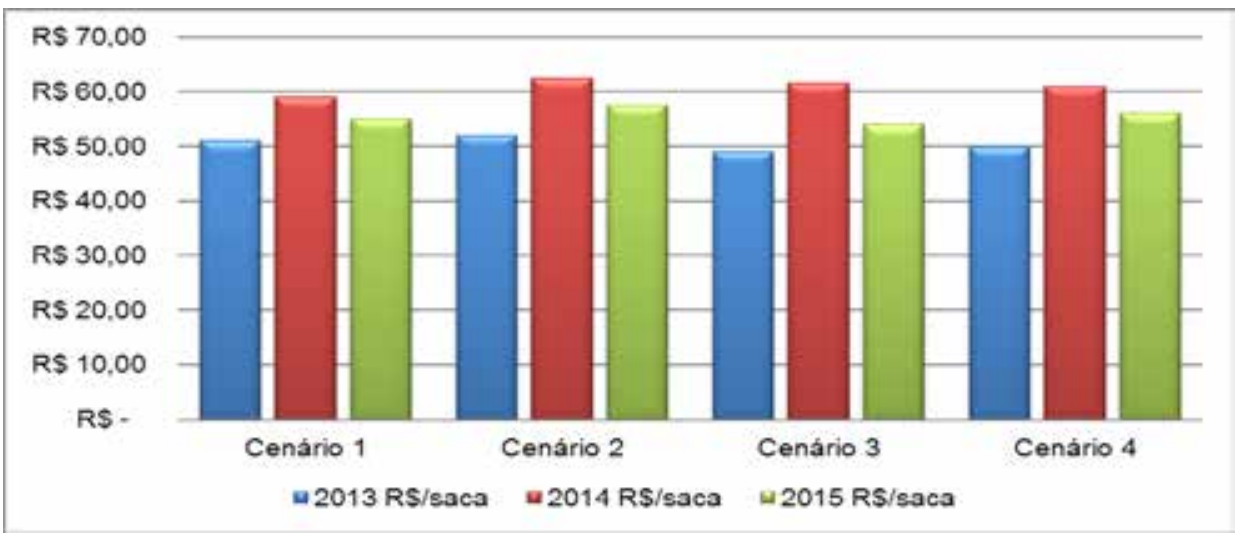

Gráfico 2. Preços da soja em três períodos distintos dos anos de 2013, 2014 e 2015 Fonte: Elaborado pelos autores com base em dados das entrevistas e CEPEA (2015).

Os dados indicam que os preços da soja são menores no mês de fevereiro, pois, neste mês, segundo o calendário agrícola, é o período de pico da colheita, sendo então o período de maior oferta da commodity. Em sua pesquisa sobre a avaliação dos ganhos logísticos com a utilização da armazenagem na região de Sorriso, no Estado do Mato Grosso, Rocha et al. (2012) apontam que nos anos analisados os preços da saca da soja foram menores no período da safra devido à maior oferta deste produto no mercado.

Com base nos preços da soja por saca o produtor decide armazenar ou vender. Neste estudo, buscou-se avaliar a receita com base na venda em quatro cenários. O cenário 1 reflete a venda sem armazenagem, ou seja, após a colheita, as vendas com 30, 60 e 90 dias após a colheita referem-se aos cenários 2, 3 e 4 respectivamente. 


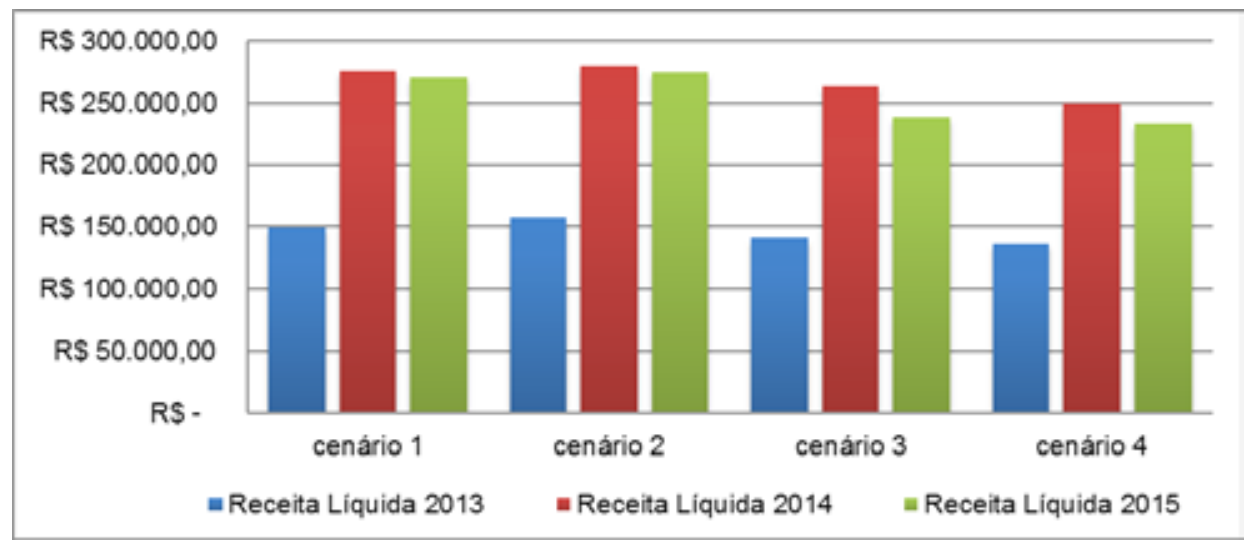

Gráfico 3. Receita Líquida com a venda da soja em cada cenário nos anos de 2013, 2014 e 2015 Fonte: Elaborado pelos autores.

Conforme dados apresentados no Gráfico 3, verifica-se que o cenário 2 apresenta maior receita líquida, devido à venda da produção em um período onde o preço da soja foi mais elevado. Embora no ano de 2014 o custo de armazenagem tenha sido maior no cenário 2 , o preço da soja nesse período foi o maior praticado em todos os cenários analisados.

Ao avaliar a receita bruta nos diferentes cenários de sua pesquisa, Rocha et al. (2012) perceberam que as maiores receitas brutas aconteceram em cenários diferentes. Em condição de armazenagem, nos anos de 2009, 2010 e 2011, apenas em 2011 em março a receita foi maior, nos outros anos o mês de junho apresentou a maior receita.

Para que se chegasse ao objetivo deste estudo, foi preciso agrupar os custos de frete e armazenagem, nos cenários em que existirem, reduzindo estes valores das receitas pertinentes a cada cenário. Nos Gráficos 4, 5 e 6 são apresentados os valores por ano para melhor compreensão. 


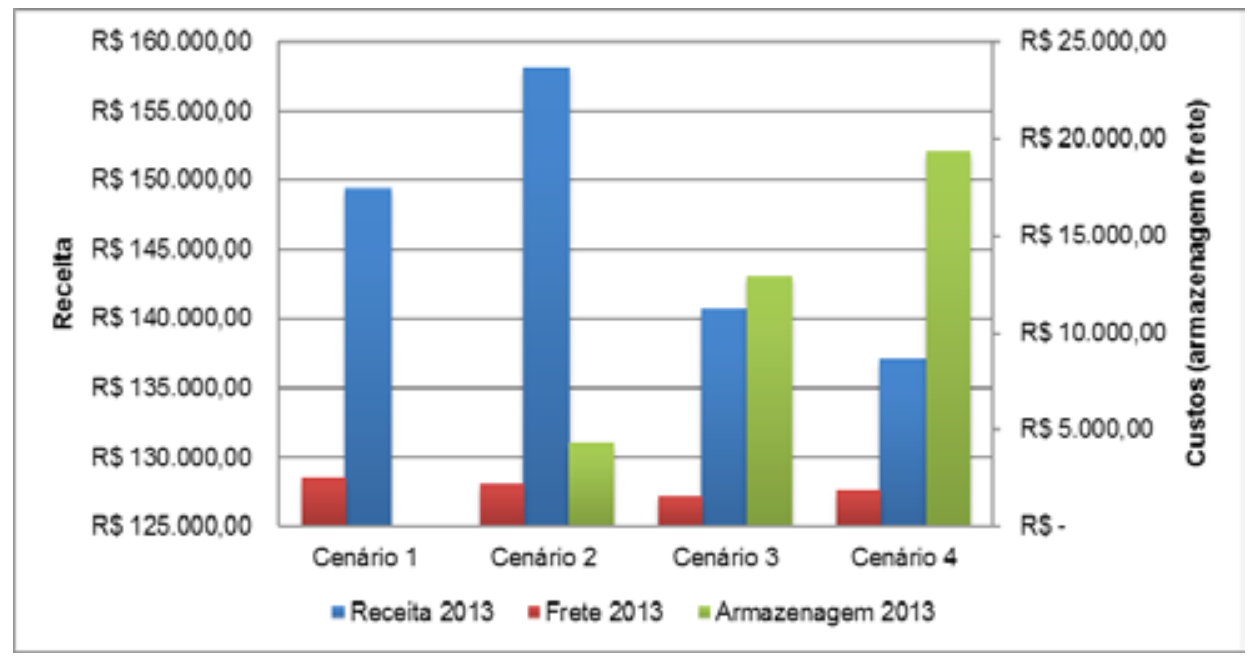

Gráfico 4. Receita Bruta e Custos de Frete e Armazenagem de cada cenário no ano de 2013 Fonte: Elaborado pelos autores.

Reduzindo os custos com armazenagem e frete no ano de 2013 a maior receita é percebida quando acontece a armazenagem da soja após a colheita até a segunda quinzena do mês de março, o que compreende o cenário 2. Neste cenário, o custo de armazenagem é menor, o valor do frete pago é o segundo menor, e a receita decorrente do melhor preço da saca de soja é maior, proporcionando maiores ganhos financeiros para o produtor. 


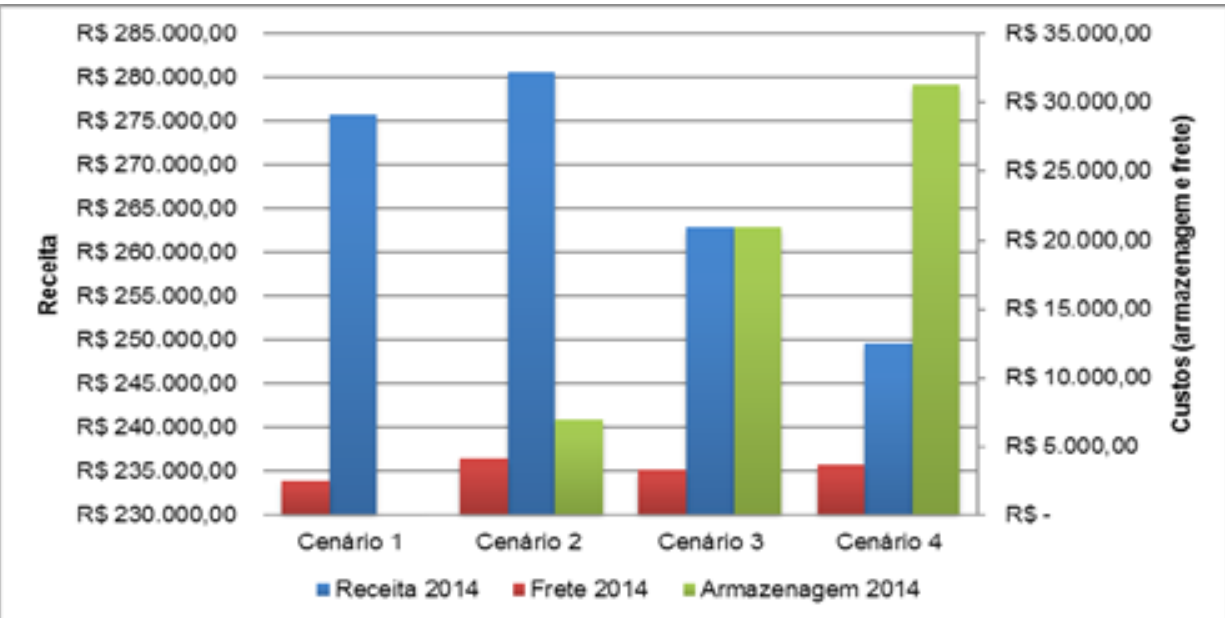

Gráfico 5. Receita Bruta e Custos de Frete e Armazenagem de cada cenário no ano de 2014 Fonte: Elaborado pelos autores.

Para o ano de 2014 o cenário 2 apresentou melhor vantagem para o produtor, pois com o preço da soja mais elevado e o menor custo de armazenagem, devido ao menor prazo de tempo, a lucratividade do produtor foi maior, comparada aos demais cenários, e suficiente para cobrir os custos com fretes.

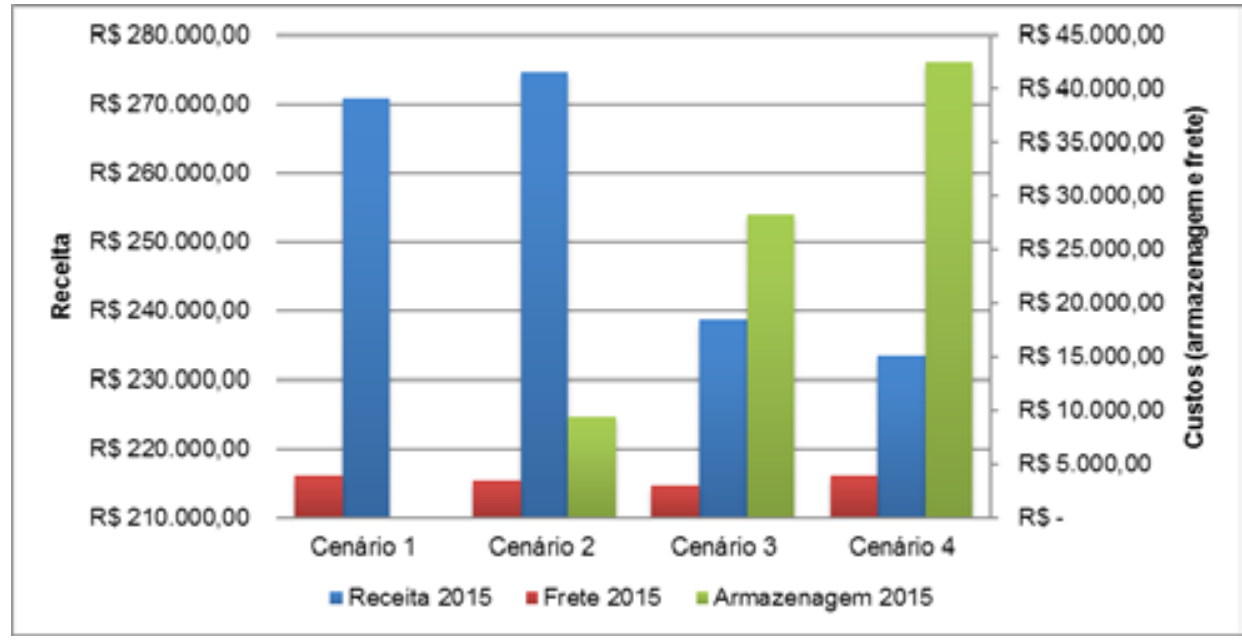

Gráfico 6. Receita Bruta e Custos de Frete e Armazenagem de cada cenário no ano de 2015 Fonte: Elaborado pelos autores. 
Quando analisados os dados do ano de 2015, foi possível perceber que o custo maior de armazenagem ocorre no cenário 4, mesmo período que o produtor obteve menor receita.

Os valores que proporcionam maiores ganhos financeiros, onde o produtor consegue vender a sua produção com o melhor preço e obter menores custos, são referentes ao cenário 2, quando a armazenagem acontece por 30 dias, como apresentado nos anos de 2014 e 2013 e a venda ocorre no momento de maior preço da saca de soja.

Com base nos dados obtidos com esta pesquisa foi possível perceber que a utilização de armazenagem diminui a rentabilidade do produtor e quanto mais longo o período de venda da soja menor são os valores pagos por saca. Resultados também obtidos por Rocha et al. (2012) corroboram com esta pesquisa, pois apresentaram que nos anos de 2010 e 2011, no município de Sorriso (MT), foi mais vantajoso vender a produção logo após a colheita, sem armazenagem e que apenas em 2009 a venda após 30 dias de armazenagem trouxe resultados de receita maiores.

Rocha et al. (2012) afirmam ainda que a estratégia de armazenagem deve ser cautelosa pois, embora diminua os custos de transporte, pode não gerar receitas satisfatórias. Assunto discutido também por Dambrosio et al. (2009), pois ressaltam que os custos de armazenagem variam de safra para safra e que estes custos podem comprometer as receitas, avaliando em sua pesquisa a utilização de armazéns próprios.

Tramontina, Talamini e Ferreira (2008) tratam o assunto armazenagem como uma necessidade do produtor, pois ao armazenar sua produção o mesmo deixa de ser um tomador de preço e passa a ser o agente negociador da sua produção. Isso se deve porque, segundo os autores, o Brasil como segundo maior produtor de grãos não possui capacidade estática de armazenagem suficiente, se comparada ao nível, por exemplo, de outro grande produtor como os Estados Unidos.

Todavia, além dos custos de armazenagem, o sojicultor ainda enfrenta custos elevados ao transportar sua produção, pois, conforme Santos et al. (2013) ao analisar o mercado e a conduta dos terminais intermodais localizados no corredor logístico da região Centro-Oeste, apontam que este setor é altamente concentrado, caracterizado por uma estrutura de mercado oligopolista. Embora o crescimento da 
produção de grãos no Brasil e Centro-Oeste tenha sido elevado, isso não se reflete nos investimentos em infraestrutura logística (SILVA; MENEZES, 2008; SANTOS et al., 2013).

Desta forma, estes autores corroboram com os resultados obtidos com a pesquisa em Amambai, pois a decisão de armazenar por um curto período de tempo após a colheita proporciona ao produtor de soja maior poder de negociação da sua produção.

\section{CONSIDERAÇÕES FINAIS}

A produção de soja apresenta crescimento no município de Amambai tanto em produtividade quando de área plantada. É importante ressaltar que os entrevistados afirmam que o uso da armazenagem em silos de cooperativas é uma estratégia de garantias futuras, a fim de assegurar o poder de negociação devido à oscilação dos preços da saca nas entressafras. Porém a incerteza de quanto tempo armazenar a produção é algo percebido na maioria dos produtores rurais, principalmente entre os pequenos.

Os custos de armazenagem e frete possuem grande influência na receita final do produtor, o que torna a decisão de vender ou armazenar mais complexa, não bastando apenas observar o preço da saca da soja que está sendo praticado no mercado, ou decidir apenas quando o valor do frete estiver menor. Na maioria dos casos, o conjunto de informações colabora para uma decisão mais assertiva.

A necessidade de armazenagem se fez presente nos anos-safra analisados, pois após a colheita os preços da soja são menores devido ao aumento da oferta. Com relação aos ganhos logísticos o cenário 2 foi o que apresentou melhores resultados, e no ano de 2014 a rentabilidade ao produtor foi maior, devido alguns fatores favoráveis como preços mais elevados, custo de armazenagem reduzido, para períodos curtos, e preços de fretes semelhantes aos praticados na colheita.

Considerando os resultados obtidos na pesquisa, é possível concluir que, para obter maior ganho logístico, o produtor pode armazenar sua produção até 30 dias após a colheita, representado pelo cenário 2. Dessa forma, a pesquisa confirma 
a hipótese deste estudo, de que a soja deve ser comercializada quando o preço de venda for maior, possibilitando assim ao produtor obter maiores ganhos logísticos. Entretanto, identificou-se a necessidade de analisar também os custos com frete e armazenagem, pois estes influenciam nos ganhos logísticos.

A pesquisa ainda aponta a necessidade de análise futura com relação às outras possibilidades de cenários que possam existir, além de avaliar os custos provenientes do destino da soja após a comercialização na cooperativa, ou seja, até os portos para exportação.

\section{AGRADECIMENTOS}

Os autores agradecem em especial à Coordenação de Aperfeiçoamento de Pessoal de Nível Superior (CAPES) e à Fundação de Apoio ao Desenvolvimento do Ensino, Ciência e Tecnologia do Estado de Mato Grosso do Sul (FUNDECT), pelo apoio financeiro para a realização da pesquisa.

\section{REFERÊNCIAS}

ALICEWEB. Exportação. 2015. Disponível em: < http://aliceweb.mdic.gov.br/> . Acesso em: 27 jul. 2015.

BISQUERRA, R.; SARRIERA, J. C.; MARTÍNEZ, F. Introdução à estatística. Porto Alegre: Artmed, 2004.

CONAB. Capacidade estática dos armazéns. 2015c. Disponível em: < http://www. conab.gov.br/conteudos.php?a =1077\&t=2> . Acesso em: 19 out. 2015.

CONAB. Indicadores da agreopcuária. 2015a. Disponível em: < http://www.conab. gov.br/conteudos.php?a=1522\&t=2>. Acesso em: 14 jun. 2015.

CONAB. Levantamentos de Safra. 2015b. Disponível em: < http://www.conab.gov. br/conteudos.php?a=1253\&> . Acesso em: 09 jul. 2015. 
CORREA, V. H. C.; RAMOS, P. A precariedade do transporte rodoviário brasileiro para o escoamento da produção de soja do Centro-Oeste: situação e perspectivas. Revista de Economia e Sociologia Rural. v. 48, n. 2, p. 447-472, 2010.

DAMBrosio, M. A. et al. Custos da Padronização e Armazenagem da Soja em Armazém Próprio no Município de Sorriso/MT. Contabilidade \& Amazônia, v. 2, n. 1, p. 118-133, 2012.

ESALQ/USP. Indicadores de preços. 2015. Disponível em: < http://cepea.esalq.usp. br/indicador/>. Acesso em: 12 out. 2015.

ESALQ-LOG. Mensuração da ineficiência logística no agronegócio Paranaense. Projeto Benin - Produto 1. 2014. Disponível em: <http://www.sistemafaep. org.br/wp-content/uploads/2014/06/Projeto-Benin-Produto-Unificado-finalmar\%C3\%A7o-2014.pdf> . Acesso em: 16 out. 2015.

FAGUNDES, M. B. B.; SIQUEIRA, R. P. Caracterização do sistema agroindustrial da soja em Mato Grosso do Sul. Revista de Política Agrícola, v. 22, n. 3, p. 58-72, 2013.

GALVAN, L. et al. Levantamento de produtividade da cultura da soja para a safra 2011/12 em Mato Grosso do Sul. 2013. Disponível em: < http://famasul.com.br/ public/area-produtor/818-levantamento-de-produtividade-da-cultura-da-soja-para-asafra-2011-2012-em-ms.pdf> . Acesso em: 16 out. 2015.

HIRAKURI, M. H.; LAZZAROTTO, J. J. O agronegócio da soja nos contextos mundial e brasileiro. Londrina: Embrapa Soja publicação, n. 349, 2011.

IBGE. Agricultura. 2015. Disponível em: < http://www.sidra.ibge.gov.br/bda/agric/ default.asp? $\mathrm{z}=\mathrm{t} \& \mathrm{o}=11 \& \mathrm{i}=\mathrm{P}>$. Acesso em: 12 out. 2015.

MINISTÉRIOS DOS TRANSPORTES. Banco de Informações e Mapas de Transportes - BIT. 2015. Disponível em: < http://www2.transportes.gov.br/bit/01-inicial/index. html $>$. Acesso em: 16 out. 2015.

NOGUEIRA JUNIOR, S.; NOGUEIRA, E. A. Centrais regionais de armazenagem como 
apoio à comercialização de grãos. Informações Econômicas, São Paulo, v. 37, n. 7, 2007.

PAVÃO, E. S. Formação, estrutura e dinâmica da economia do Mato Grosso do Sul no contexto das transformações da economia brasileira. 2005. $250 \mathrm{f}$. Dissertação (Mestrado) - Universidade Federal da Grande Dourados, Dourados, 2005.

PREFEITURA DE AMAMBAI. Dados Oficiais. 2015. Disponível em: < http://www. amambai.ms.gov.br/cidade.php/>. Acesso em: 27 jul. 2015.

PRODANOV, C. C.; FREITAS, E. C. Metodologia do trabalho científico: métodos e técnicas da pesquisa e do trabalho acadêmico. 2. ed. Novo Hamburgo: Feevale, 2013.

ROCHA, F. V. et al. Avaliação dos ganhos logísticos com a utilização da armazenagem entre os anos 2009 e 2011. In: CONGRESSO DA SOBER, 50., 2012, Vitória. Anais eletrônicos... Vitória: ESALQ-LOG, 2012. Disponível em: <http:/esalqlog. esalq.usp.br/wp-content/uploads/2015/05/Avalia\%C3\%A7\%C3\%A3o-dos-ganhos$\log \% \mathrm{C} 3 \%$ ADsticos-com-a-utiliza\%C3\%A7\%C3\%A3o-da-armazenagem-entre-os-anosde-2009-e-2011.pdf > . Acesso em: 12 out. 2015.

SANTOS, L. et al. Análise da estrutura de mercado e da conduta dos terminais intermodais do corredor logístico de grãos da região centro-oeste. Revista em Agronegócio e Meio Ambiente, v. 6, n. 2, p. 271-287, 2013.

SEPAF. Atraso no plantio de soja aumenta produtividade do grão em MS. 2015. Disponível em: <http://www.sepaf.ms.gov.br/atraso-no-plantio-de-soja-aumentaprodutividade-do-grao-em-ms/> . Acesso em: 12 out. 2015.

SIARMA. Sistema de Informações de Armazenagem. 2015. Disponível em: $<$ http://siarma.esalq.usp.br/siarma/?la=pt>. Acesso em: 12 out. 2015.

SIFRECA. Sistema de Informações de Fretes. 2015. Disponível em: <http:// esalqlog.esalq.usp.br/sifreca/>. Acesso em: 12 out. 2015. 
SILVA, M. S.; MENEZES, T. M. Corredor de escoamento noroeste: alternativa logística para produtores agrícolas das regiões centro e norte do estado do Mato Grosso. Revista em Agronegócio e Meio Ambiente, v. 1, n. 1, p. 37-44, 2007.

TRAMONTINA, L.; TALAMINI, E.; FERREIRA, G. M. O impacto da armazenagem da soja na propriedade rural sobre os preços de mercado da commodity e na ampliação da capacidade de armazenamento. In: CONGRESSO DA SOBER, 46., 2008, Rio Branco. Anais eletrônicos... Rio Branco: SOBER, 2008. Disponível em: < http:// www.sober.org.br/palestra/9/811.pdf > . Acesso em: 12 out. 2015.

USDA. Production, Supply and Distribution Online. 2015. Disponível em: < http://apps.fas.usda.gov/psdonline/> Acesso em: 27 jul. 2015.

Recebido em: 04 de novembro de 2015 Aceito em: 23 de março de 2016 